\title{
Analysis of Process Parameters and Performance Test for Fabricating Stainless-steel Metal Microneedles
}

\author{
Xiao-Xiao Yan, ${ }^{1 *}$ Gang Tang, ${ }^{1,2}$ Rui Hu, ${ }^{1}$ Bin Yang, ${ }^{2}$ Li-Ling Zhang, ${ }^{1}$ and Bin $\mathrm{Xu}^{1,2}$ \\ ${ }^{1}$ Jiangxi Province Key Laboratory of Precision Drive and Control, \\ Department of Mechanical and Electrical Engineering, \\ Nanchang Institute of Technology, Nanchang 330099, China \\ ${ }^{2}$ National Key Laboratory of Science and Technology on Micro/Nano Fabrication, \\ Department of Micro/Nano Electronics, Shanghai Jiao Tong University, Shanghai 200240, China
}

(Received October 20, 2017; accepted January 4, 2018)

Keywords: metal microneedles, drug delivery, dicing, electrochemical corrosion

Using microneedles to transport drugs is one of the new, painless, and highly efficient transdermal drug delivery methods, which has made great strides in recent years. However, many hollow and solid microneedles are usually made of silicon and polymer materials that have poor mechanical properties. To improve their strength and reliability, in this study, metal microneedles were fabricated by dicing and electrochemical corrosion. Firstly, the process parameters of electrochemical corrosion, including current and solution, were discussed and analyzed in detail for fabricating microneedles with sharp tips. Secondly, the performance test of microneedles was carried out. In a force test, these microneedles could penetrate artificial skin and rat skin, and the skins remained intact. In an in vitro transdermal drug delivery test, the amount of permeated flux of bovine serum albumin (BSA) through treated rat skin increased by 5 times of the untreated ones.

\section{Introduction}

Puncturing the skin deeply to deliver liquid drugs into the body of an organism through a hollow needle has been the most common invasive medical procedure for over 150 years. ${ }^{(1)}$ However, these traditional hypodermic needles often results into uncomfortable pain, infection, overdose, and other hazardous outcomes because of their large size. During the past two decades, microneedles have been focused on and studied widely to replace the traditional hypodermic needle for drug delivery, such as insulin, vaccines, and proteins. ${ }^{(2-6)}$ They penetrate skin to conquer the diffusion barrier of the stratum corneum (SC) of the outer skin with painless and accurate dosing owing to heights of less than $1 \mathrm{~mm}$ and diameters of 40-100 $\mu \mathrm{m}$ with submicron tip radius. ${ }^{(7)}$ In addition, the microneedle fabrication process is highly accurate, reproducible, and moderate in cost. ${ }^{(8,9)}$

Initially, many microneedles were based on silicon materials because silicon can be processed easily and effectively with the development of the micro-electromechanical system (MEMS). ${ }^{(10-12)}$

*Corresponding author: e-mail: qwwxiao@sjtu.edu.cn

http://dx.doi.org/10.18494/SAM.2018.1781 
Recently, polymer microneedles have been fabricated for drug delivery. ${ }^{(13-15)}$ However, even if these microneedles are successfully fabricated and tested for delivering drugs, their inherent shortcomings, such as poor mechanical property, limit their further development. In comparison, metal microneedles have high strength, but their fabrication process, which includees electroplating or laser machining, is very costly and complex such that they must be further developed and studied for popularization. ${ }^{(16,17)}$

In our previous work, we proposed one novel, low-cost method of fabricating stainlesssteel metal microneedles by the hybrid method of mechanical dicing (MD) and electrochemical corrosion $(\mathrm{EC}){ }^{(18)}$ However, the detailed fabrication process parameters are needed to be analyzed for their application. Therefore, in this paper, the main process parameters of shaping microneedles, namely current and solution concentration of the EC, were discussed in detail, and the force test and transdermal drug delivery test were performed to evaluate the performances of these microneedles. The results of the force test and the transdermal drug delivery test demonstrated that the fabricated microneedles with the analyzed parameters were safe and practicable, as expected.

\section{Fabrication Process}

The elaborate fabrication process was proposed in our previous paper. ${ }^{(18)}$ The fabrication process can be summarized as follows. Firstly, one wafer of stainless steel with two polished sides, a thickness of $2 \mathrm{~mm}$, and a diameter of $75 \mathrm{~mm}$, was prepared [Fig. 1(a)]. Secondly, microcolumns were created using a dicing saw with a blade whose rotating speed is $14000 \mathrm{rpm}$ [Fig. 1(b)]; finally, microneedles with sharp tips were achieved by electrochemical corrosion. The dicing saw is an automatic machine that can cut silicon easily and quickly, and the shape of the cut microcolumns is determined by the blades. During the cutting, the stainless-steel wafer was fixed on a rectangular glass sheet of size $100 \mathrm{~mm} \times 100 \mathrm{~mm}$ with melted wax, and the sheet was put on the cutting platform of the dicing saw. The speed of the blades in the dicing saw was approximately $14000 \mathrm{rpm}$, and its feed speed was $6 \mathrm{~mm} / \mathrm{s}$. Therefore, the saw can process a 75-mm-diameter silicon wafer to quickly and steadily to form microcolumns for large-volume production.

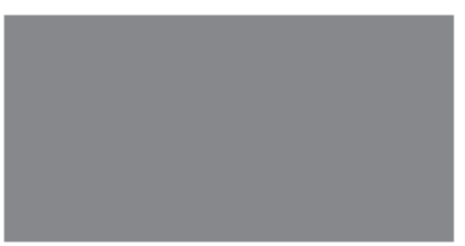

(a)

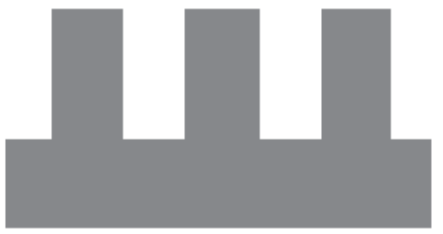

(b)

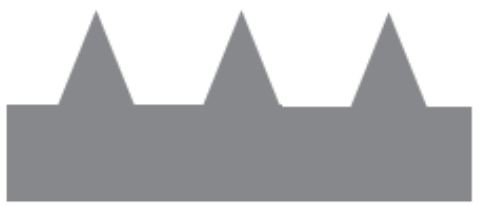

(c)

Fig. 1. Fabrication process: (a) prepare one stainless-steel wafer, (b) cut microcolumns, and (c) shape microneedles. 


\section{Results and Discussion}

\subsection{EC current}

During the fabrication process, the EC current and solution concentration are the main impact process parameters in shaping the body and tip of microneedles. Generally speaking, the microcolumn body size decreased quickly for rapid EC with large current. The relationship between the EC speed and the current is shown in Fig. 2. It shows that, under room temperature and in a mixture solution $\left(\mathrm{H}_{3} \mathrm{PO}_{4}: \mathrm{H}_{2} \mathrm{SO}_{4}: \mathrm{H}_{2} \mathrm{O}=1: 3: 6\right)$, the EC speed was about $12 \mu \mathrm{m} / \mathrm{min}$ with 3 A current and about $5 \mu \mathrm{m} / \mathrm{min}$ with $1.5 \mathrm{~A}$ current. Therefore, a large current, such as $3 \mathrm{~A}$, caused the microcolumn size to decrease quickly, while a small current, such as $1.5 \mathrm{~A}$, modified the body size gradually.

Moreover, the current also impacted the surface roughness of microcolumns (Fig. 3). Figure 3 shows the images of the same microcolumns etched for $5 \mathrm{~min}$ in the solution $\left(\mathrm{H}_{3} \mathrm{PO}_{4}: \mathrm{H}_{2} \mathrm{SO}_{4}: \mathrm{H}_{2} \mathrm{O}\right.$ $=1: 3: 6$ ); the larger the current, the rougher the microcolumn surface.

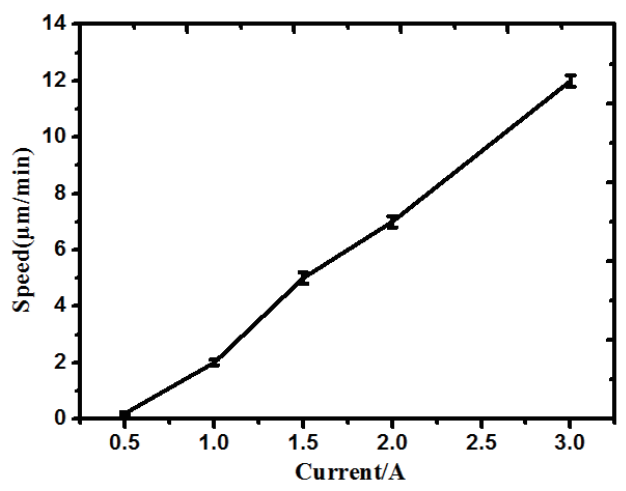

Fig. 2. Relationship between current and $\mathrm{EC}$ speed (solution $\mathrm{H}_{3} \mathrm{PO}_{4}: \mathrm{H}_{2} \mathrm{SO}_{4}: \mathrm{H}_{2} \mathrm{O}=1: 3: 6$ ). Each value represents the mean (standard deviation) of three replicates.

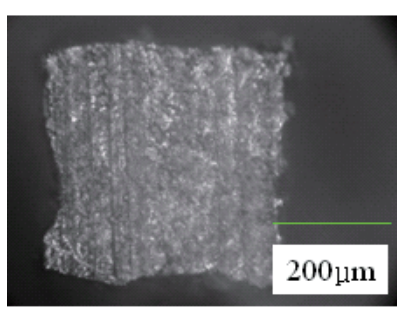

(a)

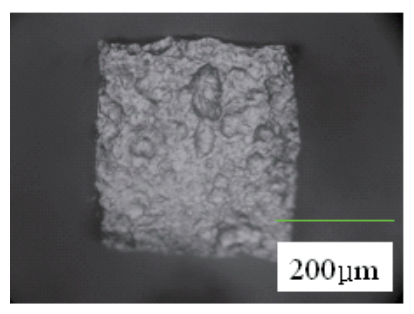

(d)

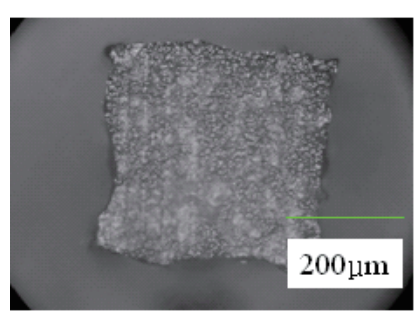

(b)

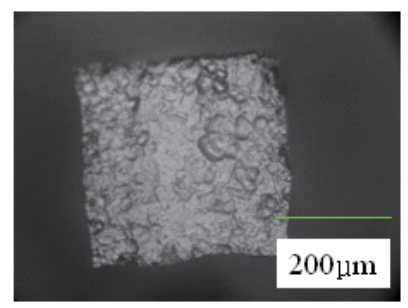

(e)

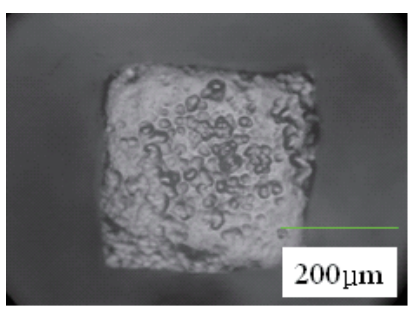

(c)

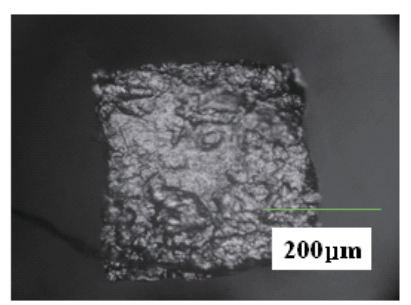

(f)

Fig. 3. (Color online) Images of microcolumn patches for different currents: (a) 0, (b) 0.5, (c) 1, (d) 1.5, (e) 2, and (f) 3 A. 


\subsection{EC solution}

The solution is another important parameter that affects the EC speed and the shape of microneedles. Table 1 lists the EC speed under different volume ratios of $\mathrm{H}_{3} \mathrm{PO}_{4}, \mathrm{H}_{2} \mathrm{SO}_{4}$, and $\mathrm{H}_{2} \mathrm{O}$. When the volume of $\mathrm{H}_{3} \mathrm{PO}_{4}$ was larger than that of $\mathrm{H}_{2} \mathrm{SO}_{4}$, the speed was very low, but when $\mathrm{H}_{2} \mathrm{SO}_{4}$ was over $36.4 \%$, the speed was steady at about $5 \mu \mathrm{m} / \mathrm{min}$.

At the same current, different volume ratios of the solution lead to different surface roughnesses of the microcolumns. Figure 4 shows the microcolumn images of patches before EC [Fig. 4(a)] and after EC [Fig. 4(b)] in the solution $\mathrm{H}_{3} \mathrm{PO}_{4}: \mathrm{H}_{2} \mathrm{SO}_{4}: \mathrm{H}_{2} \mathrm{O}=3: 3: 6$ with the current of $1.5 \mathrm{~A}$ in $3 \mathrm{~min}$. It is observed that the surface of the stainless steel patch after EC was very rough. However, under the same current and etch time, when $\mathrm{H}_{3} \mathrm{PO}_{4}: \mathrm{H}_{2} \mathrm{SO}_{4}: \mathrm{H}_{2} \mathrm{O}$ was changed to 1:3:6, the surface was very smooth after EC, as shown in Figs. 5(a) and 5(b).

Table 1

Contents of solution and EC speed.

\begin{tabular}{cccc}
\hline $\mathrm{H}_{2} \mathrm{SO}_{4}(\mathrm{ml})$ & $\mathrm{H}_{3} \mathrm{PO}_{4}(\mathrm{ml})$ & $\mathrm{H}_{2} \mathrm{O}(\mathrm{ml})$ & Speed $(\mu \mathrm{m} / \mathrm{min})$ \\
\hline 20 & 10 & 60 & 4 \\
30 & 40 & 60 & 0.5 \\
30 & 30 & 60 & 0.6 \\
30 & 20 & 60 & 6 \\
30 & 10 & 60 & 5 \\
40 & 10 & 60 & 5.2 \\
50 & 10 & 60 & 5.3 \\
\hline
\end{tabular}

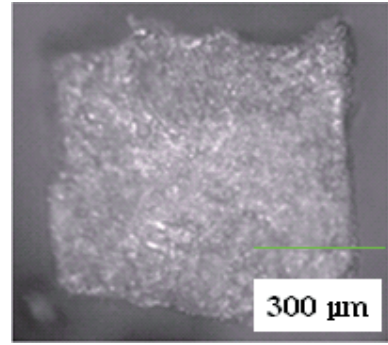

(a)

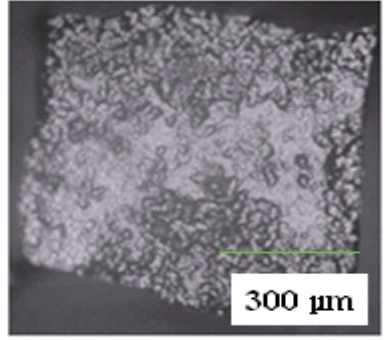

(b)

Fig. 4. (Color online) Images of patches in the solution $\mathrm{H}_{3} \mathrm{PO}_{4}: \mathrm{H}_{2} \mathrm{SO}_{4}: \mathrm{H}_{2} \mathrm{O}=3: 3: 6$ (a) before $\mathrm{EC}$ and (b) after EC.

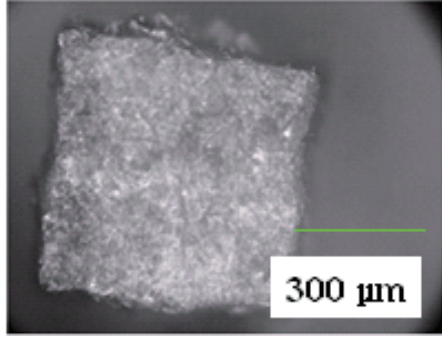

(a)

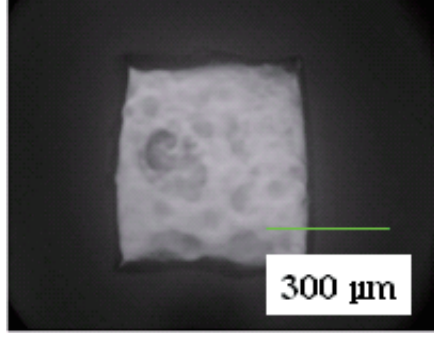

(b)

Fig. 5. (Color online) Images of patches in the solution $\mathrm{H}_{3} \mathrm{PO}_{4}: \mathrm{H}_{2} \mathrm{SO}_{4}: \mathrm{H}_{2} \mathrm{O}=1: 3: 6$ (a) before $\mathrm{EC}$ and (b) after EC. 
Therefore, in order to obtain microneedles with a sharp tip and smooth body, the volume ratio of the mixture solution was selected as $\mathrm{H}_{3} \mathrm{PO}_{4}: \mathrm{H}_{2} \mathrm{SO}_{4}: \mathrm{H}_{2} \mathrm{O}=1: 3: 6$. This mixture solution not only reduced the size of the metal body quickly, but also made the surface smooth and clean. For example, cut tapered microcolumns, which had the height of $500 \mu \mathrm{m}$, bottom width of $300 \mu \mathrm{m}$, and space size of $400 \mu \mathrm{m}$, were made by bevel blade dicing [Fig. 6(a)]. To obtain microneedles with sharp tips and smooth bodies, first, the microcolumns were etched at $3 \mathrm{~A}$ current in $11 \mathrm{~min}$, then at $1.5 \mathrm{~A}$ current in $8 \mathrm{~min}$, and finally at $1 \mathrm{~A}$ current in $5 \mathrm{~min}$ [Fig. 6(b)]. The fabricated microneedle height was about $400 \mu \mathrm{m}$ and the bottom size was about $300 \mu \mathrm{m}$.

\section{Performance Test}

\subsection{Force test}

The fabricated $15 \times 15$ microneedle array patch [Fig. 6(b)] was utilized to test the force property on a custom-made instrument. ${ }^{(19)}$ The test conditions were as follows: (1) artificial skin (polyurethane, $0.35 \mathrm{~mm}$, Shore $85 \pm 10$, Taobao, China) or rat skin was fixed on a platform; (2) the constant insert speed was $1 \mathrm{~mm} / \mathrm{min}$; (3) the loading forces ranged from 0 to $10 \mathrm{~N}$. Rat skin $0.5-1 \mathrm{~mm}$ thick was excised from the abdominal skin of rats after they were sacrificed. The animals were given free access to food and water ad libitum unless otherwise noted. All procedures were approved by the Laboratory Animal Use Committee of Shanghai Jiao Tong University School of Pharmacy. All efforts were made to reduce the number of animals used, minimize their suffering, and utilize alternative in vivo techniques if available.

The test data of force and depth are shown in Fig. 7. Under the force of $10 \mathrm{~N}$, the microneedles pierced $260 \mu \mathrm{m}$ into the artificial skin and $145 \mu \mathrm{m}$ into the rat skin, respectively, demonstrating that the microneedles could sufficiently penetrate the SC (thickness of 20-40 $\mu \mathrm{m})$ of the skin.

To observe clearly the rat skin wounds created by microneedles, Rhodamine B $(5 \mathrm{mg} / \mathrm{ml})$ (Shanghai Yuanye Bio-Technology Co., Ltd., China) and Lutrol F-68 (2 mg/ml) (Basf) (w:w $=1: 1)$ were coated on the surfaces of microneedles. The microneedles were immersed into this mixture solution for $30 \mathrm{~s}$, and then dried at room temperature for $24 \mathrm{~h}$. Then, these microneedles were utilized to pierce into the skins and the wounds were observed using a

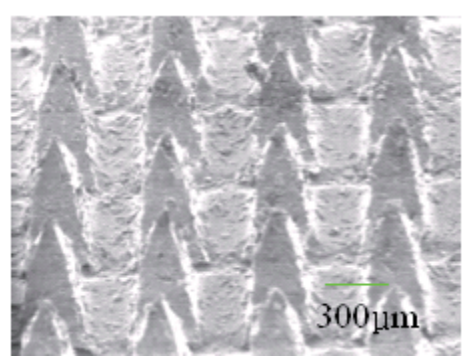

(a)

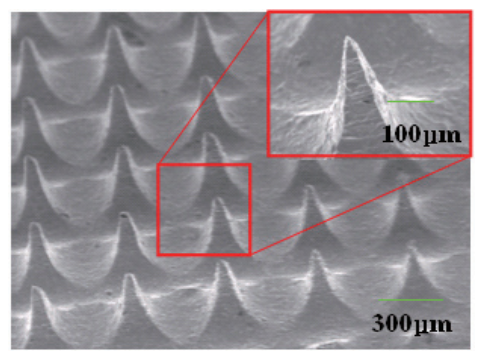

(b)

Fig. 6. (Color online) Scanning electron microscopy images of cut tapered microcolumns and shaped microneedles: (a) cut microcolumns and (b) microneedles formed after etching of microcolumns. 


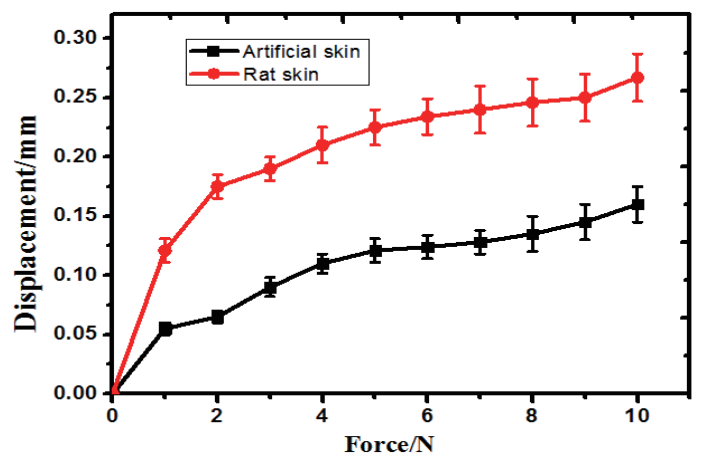

Fig. 7. (Color online) Relationship between force and depth. Each value represents the mean (standard deviation) of three replicates.

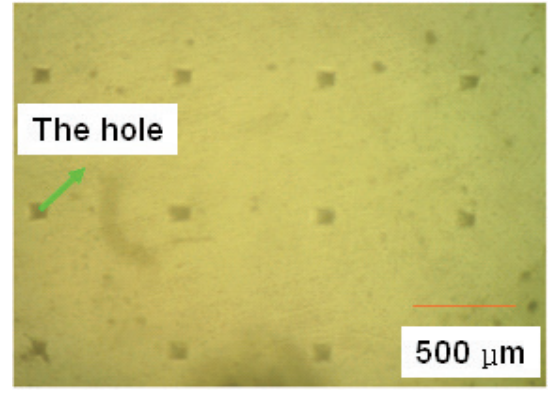

(a)

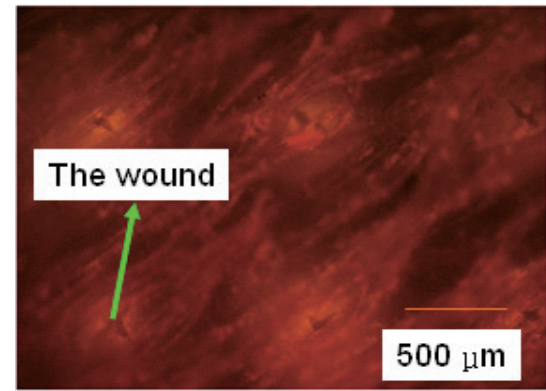

(b)

Fig. 8. (Color online) Holes in the (a) artificial skin and (b) rat skin.

fluorescence microscope (Olympus BX61). During the test, an artificial skin layer was placed under the rat skin to prevent the microneedles from being deformed.

The holes in the artificial skin and rat skin that were penetrated by the microneedles are shown in Figs. 8(a) and 8(b), respectively. This result indicated that the metal microneedles could penetrate skin and create passages for drugs delivery effectively.

\subsection{Permeation study and results}

The important function of microneedles is to transport macromolecular drugs, such as protein and insulin. Therefore, the protein bovine serum albumin (BSA, $66 \mathrm{kDa}$, Shanghai Yuanye Bio-Technology Co., Ltd., China) was selected to assess the permeation ability of rat skin using these microneedles for in vitro transdermal drug delivery. ${ }^{(19,20)}$ After being treated by microneedles (piercing speed of $1 \mathrm{~mm} / \mathrm{min}$, piercing force of $10 \mathrm{~N}$ ), the rat skin was placed on a Franz diffusion cell (Shanghai Heqi Glassware Co., Ltd., China) with a donor chamber and an acceptor chamber. The SC faced the donor chamber, and the epidermis faced the acceptor chamber with a volume of $15 \mathrm{ml}$. The donor chamber was filled with the $6 \mathrm{ml}$ of highconcentration-BSA PBS solution $(2 \mathrm{mg} / \mathrm{ml})$, while the acceptor chamber was filled with PBS. 


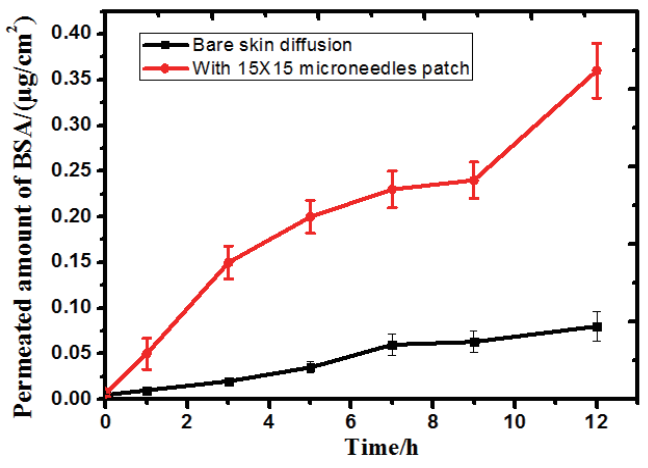

Fig. 9. (Color online) In vitro transdermal drug release profile of BSA through rat skin. Each value represents the mean $(n \geq 3)$ with standard deviation.

The PBS in the acceptor chamber was stirred to disperse the BSA into the PBS homogeneously and the PBS temperature was $37^{\circ} \mathrm{C}$. This temperature was constant during the experiments. At certain time intervals, a $1 \mathrm{ml}$ sample was taken from the acceptor chamber, and then the same volume of PBS was added. Three experiments for each BSA amount were performed to obtain an average value. An ultraviolet spectrophotometer was utilized to detect the BSA. ${ }^{(19)}$

The amounts of permeated BSA with time are shown in Fig. 9. The permeated fluxes of BSA through the treated and intact skins were about 0.025 and $0.005 \mu \mathrm{g} / \mathrm{cm}^{2} / \mathrm{h}$, respectively, which indicated that the microneedle patch could increase the amounts of permeated macromolecule protein fivefold in transdermal drug delivery.

\section{Conclusions}

Stainless-steel microneedles for drug delivery were proposed and fabricated by a hybrid process of $\mathrm{MD}$ and $\mathrm{EC}$, and the main process parameters of electrochemical corrosion, namely, current and solution, were discussed and analyzed in detail. The tapered metal microcolumns could be shaped into sharp tapered microneedles by EC. The tapered tips could guarantee that microneedles pierce the skins well and easily. The piercing force test shows that the microneedles had excellent mechanical property and were highly safe. In an in vitro transdermal drug delivery test, the microneedles pierced the SC of the skins, thus improving the permeation flux of drugs through skins significantly. For example, the amount of the permeated macromolecule protein BSA increased fivefold.

\section{Acknowledgments}

This work was partly supported by the National Natural Science Foundation of China (Nos. 51565038 and 51765044), and Natural Science Foundation of Jiangxi province (Nos. 20161BAB216106 and GJJ151102). The authors are also grateful to their colleagues for their essential contributions to this work. 


\section{References}

1 D. McAllister, M. Allen, and M. Prausnitz: Annu. Rev. Biomed. Eng. 2 (2000) 289.

2 S. Henry, D. V. Mcallister, M. G. Allen, and M. R. Prausnitz: J. Pharm. Sci. 87 (1998) 922.

3 K. Ita: J. Drug Delivery Sci. Technol. 29 (2015) 16.

4 W. Martanto, S. P. Davis, N. R. Holiday, and J. Wang: Pharm. Res. 21 (2004) 9479.

5 Y. C. Kim, S. Quan, R. W. Compans, S. M. Kang, and M. R. Prausnitz: J. Controlled Release 142 (2010) 187.

6 S. P. Sullivan, N. Murthy, and M. R. Prausnitz: Adv. Mater. 20 (2008) 933.

7 H. Schaefer and T. E. Redelmeier: Skin Barrier: Principles of Percutaneous Absorption (Karger, Basel, 1996).

8 N. Wilke, A. Mulcahy, S. R. Ye, and A. Morrissey: Microelectron. J. 36 (2005) 221

9 R. Bhandari, S. Negi, and F. Solzbacher: IEEE Electronic Components and Technology Conf. (IEEE, 2008) 1306.

10 B. Stoeber and D. Liepmann: J. Microelectromech. Syst. 14 (2005) 472.

11 B. Chen, J. Wei, and C. Iliescu: Sens. Actuators, B 145 (2010) 54.

12 S. P. Narayanan and S. Raghavan: Int. J. Adv. Manuf. Technol. 93 (2017) 407.

13 S. C. Kuo and Y. Chou: Tamkang J. Sci. Eng. 7 (2004) 95.

14 S. P. Sullivan, D. G. Koutsonanos, M. P. Martin, J. W. Lee, V. Zarnitsyn, S. O. Choi, N. Murthy, R. W. Compans, I. Skountzou, and M. R. Prausnitz: Nat. Med. 16 (2010) 915.

15 R. Vecchione, S. Coppola, E. Esposito, C. Casale, V. Vespini, S. Grilli, P. Ferraro, and P. A. Netti: Adv. Funct. Mater. 24 (2014) 3512.

16 S. P. Davis, W. Martanto, M. G. Allen, and M. R. Prausnitz: IEEE Trans. Biomed. Eng. 52 (2005) 909.

17 T. Omatsu, K. Chujo, K. Miyamoto, and M. Okida: Opt. Express 18 (2010) 17967.

18 X. X. Yan, J. Q. Liu, S. D. Jiang, B. Yang, and C. Sh. Yang: IET Micro Nano Lett. 7 (2012) 1313.

19 X. X. Yan, J. Q. Liu, S. D. Jiang, B. Yang, and C. S. Yang: Microelectron. Eng. 111 (2013) 33.

20 Organization for Economic Cooperation and Development (OECD), OECD Guidelines for Testing of Chemicals, No. 428: Skin Absorption: In vitro Method (OECD, 2004). 